\title{
The Environment of Intrafamilial Offenders - A Systematic Review of Dynamics in Incestuous Families
}

\author{
Susan Alexa Pusch ${ }^{1}$, Thomas Ross ${ }^{2}$, María Isabel Fontao ${ }^{1}$ \\ [1] Department of Psychology, University of Konstanz, Konstanz, Germany. [2] Department of Psychosomatic Medicine \\ and Psychotherapy, University of Ulm, Ulm, Germany.
}

Sexual Offending: Theory, Research, and Prevention, 2021, Vol. 16, Article e5461, https://doi.org/10.5964/sotrap.5461

Received: 2020-12-17 • Accepted: 2021-10-13 • Published (VoR): 2021-12-23

Handling Editor: Martin Rettenberger, Centre for Criminology (Kriminologische Zentralstelle - KrimZ), Wiesbaden, Germany

Corresponding Author: María Isabel Fontao, Department of Psychology, University of Konstanz, Universitaetsstrasse 10, D-78464, Konstanz, Germany. E-mail: maria.fontao@uni-konstanz.de

Supplementary Materials: Materials [see Index of Supplementary Materials]

\begin{abstract}
The aim of this study was to identify family characteristics and dynamics relevant to the initiation and maintenance of intrafamilial child sexual abuse. An understanding of essential characteristics of the affected families could help to prevent such crimes. In order to provide an overview of the current state of research, a literature review based on the PRISMA criteria was conducted. For the research in the databases PsycInfo and PSYNDEX, predetermined criteria and search terms were used. Fifteen relevant articles from 1991 to 2020 were identified. The studies examined perpetratorvictim relationships, the role of the mother, the relationship between the parents and characteristics of the families in which child sexual abuse took place. Relevant core characteristics of incestuous families are dysfunctional, violent, and conflictual relationships between the parents, and between parents and children. However, these factors are often not specific to intrafamilial abuse. Only six articles published after 2000 were identified. Little evidence for each individual construct was found, so the effects should not be overestimated. Further research on intrafamilial child sexual abuse is necessary.
\end{abstract}

\section{Keywords}

intrafamilial abuse, incest, child sexual abuse, family dynamics, systematic review 


\section{Definition and Prevalence of Child Sexual Abuse}

Child sexual abuse is a widespread phenomenon with lasting social and health consequences. A meta-analysis by Stoltenborgh and colleagues (2011) showed a global prevalence rate for child sexual abuse of $11.8 \%$, with the risk for girls being more than twice as high as for boys. In a gender-representative anonymous online survey of 7,909 young adults in Germany, 8.5\% of the participants reported having suffered sexual abuse in childhood and youth (Neutze \& Osterheider, 2015). A German study conducted by Witt et al. (2018) compared the data sets of two surveys on child sexual abuse from the years 2010 with 2,504 participants and 2016 with 2,510 participants each. In 2010, 12.6\% ( $n=$ 316 ) of the participants reported having experienced sexual abuse. Using the screening version of the Childhood Trauma Questionnaire, abuse experiences were rated as mild or moderate in $6.3 \%(n=158)$, moderate to severe in $4.4 \%(n=111)$, and severe to extreme sexual abuse in $1.9 \%(n=48)$ of the participants. In 2016 , a total of $13.9 \%(n=349)$ individuals reported sexual child sexual abuse in childhood, with $6.3 \%(n=159)$ grading the abuse slight to moderate, $5.3 \%(n=133)$ moderate to severe, and 2.3\% $(n=58)$ severe to extreme.

Neutze and Osterheider (2015) found that two thirds of the affected youths and young adults had not told anybody about the abuse before they participated in the study. Only $1 \%$ of the experiences of abuse had been reported to the authorities.

\section{Intrafamilial Child Sexual Abuse}

If the perpetrator of child sexual abuse is a family member, this is referred to as intrafamilial or incestuous abuse. The incest taboo is valid across cultures, and feelings of disgust and rejection about the idea of sexual intercourse with a close relative are common among the general population (Seto et al., 2015). Incest is associated with enormous negative consequences for the victims and for incestuously conceived children. According to Latzman et al. (2011), sexual abuse by siblings is about two to five times more likely that father-daughter abuse and Carlson et al. (2006) also reported that inter-sibling abuse is the most common type of intrafamilial abuse. Conversely, according to Rice and Harris (2002) intrafamilial child sexual abuse is typically perpetrated by fathers or stepfathers.

The meta-analytical study by Stoltenborgh and colleagues (2011) showed that up to one third of the detected cases of child sexual abuse are carried out by a family member. In the above mentioned German online survey, one third of the victims reported abuse by a family member (Neutze \& Osterheider, 2015). The review by Kloppen et al. (2015) found a prevalence of child sexual abuse by a parent between $0.2-1.2 \%$ for Nordic European countries. For the year 2020, the Belgian region of Flanders reported a prevalence of $5.6 \%$ $(n=558)$ for intrafamilial abuse and $3.2 \%(n=320)$ for sexual abuse outside the family. Incest cases without clear assignment had a prevalence of 3.9\% $(n=387$; Opgroeien, 2020, p. 157). In a general population survey $(N=28,010)$ in Metropolitan France, $3.7 \%$ of the 
participants (aged 18 years or older) reported having been abused by a member of the family as a child; a higher prevalence for women (5.8\%; men: $1.5 \%$ ) was found (Bajos et al., 2021).

In the United States, a study by Finkelhor et al. (2014) found a lifetime prevalence rate for 17 year old females of $5.5 \%$ for sexual abuse by a family member. As for sexual abuse by a sibling, a former study reported that $15 \%$ of the female and $10 \%$ of the male participants in an US college sample had experienced sibling sexual abuse (Finkelhor, 1980). Interestingly, a more recent survey found a slightly lower prevalence: in computer assisted self-interviews with 1,178 male adults, 27 participants reported having been a victim of sister-brother incest (O'Keefe et al., 2014), and 25 of brother-brother incest (Beard et al., 2013).

\section{Family Characteristics and Dynamics}

Family dynamics seem to play a particularly important role in the investigation of intrafamilial abuse. Several critical constellations are discussed in the literature. Faust and colleagues (1997) found that stepfathers were more likely to sexually abuse than biological fathers. There are two potential explanations for this: first, the incest taboo might be weaker for stepfathers, because they are not blood-related to the victims; second, "step-families" often experience a higher level of stress, which increases the risk of intrafamilial abuse (Faust et al., 1997). In the case of sibling abuse, both the absence of the father and the mother are considered risk factors (Rudd \& Herzberger, 1999). Physical or psychological absence of the mother can favor intrafamilial abuse (Faust et al., 1997). Psychological abuse in the family, substance abuse by the parents, or the removal of children from the family (Tidefors et al., 2010), as well as domestic violence (Latzman et al., 2011) are significantly correlated with sibling abuse. Lack of communication skills and poor problem-solving strategies may be frequent in incestuous family structures (Madonna et al., 1991). Negative, belligerent family environments, parental rejection of children, marital problems, and lack of satisfaction with family relationships promote the occurrence of intrafamilial abuse (Salazar et al., 2005). Paveza (1988) also identified marital dissatisfaction and violence between spouses as risk factors for the occurrence of intrafamilial abuse. In dysfunctional family structures, abuse may serve the purpose of satisfying the perpetrator's emotional needs for closeness and security, which are expressed through sexual acts (Schwartz et al., 2006). Sexual contact between daughters and fathers tend to occur more frequently in family structures in which the roles of mother and daughter are reversed. If so, the mother may not be able to satisfy the emotional or sexual needs of her partner, who eventually turns to her daughter with sexual intent, because she has taken on the "mother's role" (Parker \& Parker, 1986). 


\section{Aim of This Systematic Review}

In the context of an increasing readiness to report sexual harassment and abuse as well as growing social rejection of these phenomena, competent authorities and professionals are called upon to intervene at an early stage to prevent further damage. Early identification of dysfunctional dynamics as risk factors for intrafamilial child sexual abuse could help implement preventive measures and adequate intervention strategies. The aim of this review is to identify family characteristics and dynamics that might be relevant in initiating and perpetuating intrafamilial abuse. The research question was: Which family characteristics and dynamics are related to intrafamilial child sexual abuse?

\section{Method}

This systematic review is based on the PRISMA (Preferred Reporting Items for Systematic Review and Meta-Analysis) criteria, which allow for transparency and completeness of the work (Moher et al., 2009). It focuses on family characteristics and dynamics which are related to child sexual abuse perpetrated by a family member. Other aspects of intrafamilial abuse, such as perpetrator related variables or psychosocial consequences of child sexual abuse, are not in the scope of this review.

\section{Selection Criteria}

Articles in English or German language published in peer reviewed scientific journals between 1989 and 2020 dealing with intrafamilial child sexual abuse were considered for inclusion. All types of intrafamilial perpetrators were taken into consideration (among others: father, stepfather, siblings). Although the possibility of general differences in the perpetration of intrafamilial sexual abuse depending on the relationship between perpetrator and victim could not be excluded at this point, this approach seemed adequate. As Cyr and colleagues (2002, p. 957) state, "characteristics of brother-sister incest and its associated psychosocial distress did not differ from the characteristics of father-daughter incest”. Both studies with a comparison group (e.g., intact families without child sexual abuse, families of offenders who perpetrated child sexual abuse outside their family) and those without a comparison group were included. No restrictions were made with regard to the gender of the victims. In order to keep a clear focus on intrafamilial abuse, studies reporting on both intra- and extrafamilial victims were excluded. An exception to the latter criterium was made for the meta-analysis by Martijn et al. (2020) which includes some articles dealing with offenders who abused both intrafamilial and extrafamilial victims.

Studies were included in which perpetrators were biologically or legally related to the victims (e.g., stepfathers, mother's partner, stepbrothers), as, for example, Langevin and Watson (1991) found very few differences in their comparison between biological 
and stepfathers. No further restrictions were made with regard to the degree of kinship between perpetrator and victim. The maximum age of the victim at the beginning of the abuse was set at 18 years, which corresponds to the maximum age for the offence of sexual abuse of protected persons in many western countries. Studies which did not specify the age of a victim at incest onset were excluded, unless the victims were referred to as minors or children at the beginning of the abuse. No restrictions were made with regard to the sample size.

Empirical articles and meta-analyses were included, but case studies, popular science articles or nonsystematic reviews were excluded. No structured instruments were used to assess the quality of the included studies. Initially, studies with female perpetrators were excluded, as were studies which exclusively investigated hands-off offences. For articles from 2009 onwards, however, these two criteria were removed in order to capture more recent studies. As a result, two more studies (Griffee et al., 2016; McDonald \& Martinez, 2017) were identified and included in the review.

\section{Databases and Search Strategy}

The electronic databases PsycInfo and PSYNDEX were searched. The search was carried out from 29.11.2019 to 28.01.2020 for articles between 1989 and 2019, and on the 22.04.2021 for the years 2020 and 2021. In addition, a backwards search was conducted using the references lists of the included papers.

The used search terms and combinations were: 1) intrafam* OR incest* AND 2) child* molest* OR sex* offen* OR abus* AND 3) famil ${ }^{*}$. By applying the asterisk ( ${ }^{*}$ ), all words containing the same full word or the same word stem were searched.

\section{Selection of Studies}

In the first step of the search in PsycInfo and PSYNDEX, 404 records were obtained. On the basis of article title and abstract, the eligibility of each record was checked by the lead author. In the next step, the full text of the remaining 109 articles was assessed using the criteria described above, with 15 identified as suitable for inclusion. By removing the criteria "only hands-on offences" and "only male offenders" from 2009 up, two additional articles were identified.

\section{Risk of Bias}

In order to reduce the risk of bias in this review, the recommendations of the PRISMA statement were applied. The successive steps in the identification and selection of articles are described in Figure 1. Due to heterogeneity of the original studies (e.g., with respect to designs, methods and instruments) the risk of bias cannot be calculated. 


\section{Figure 1}

Study Selection Based on the PRISMA Criteria

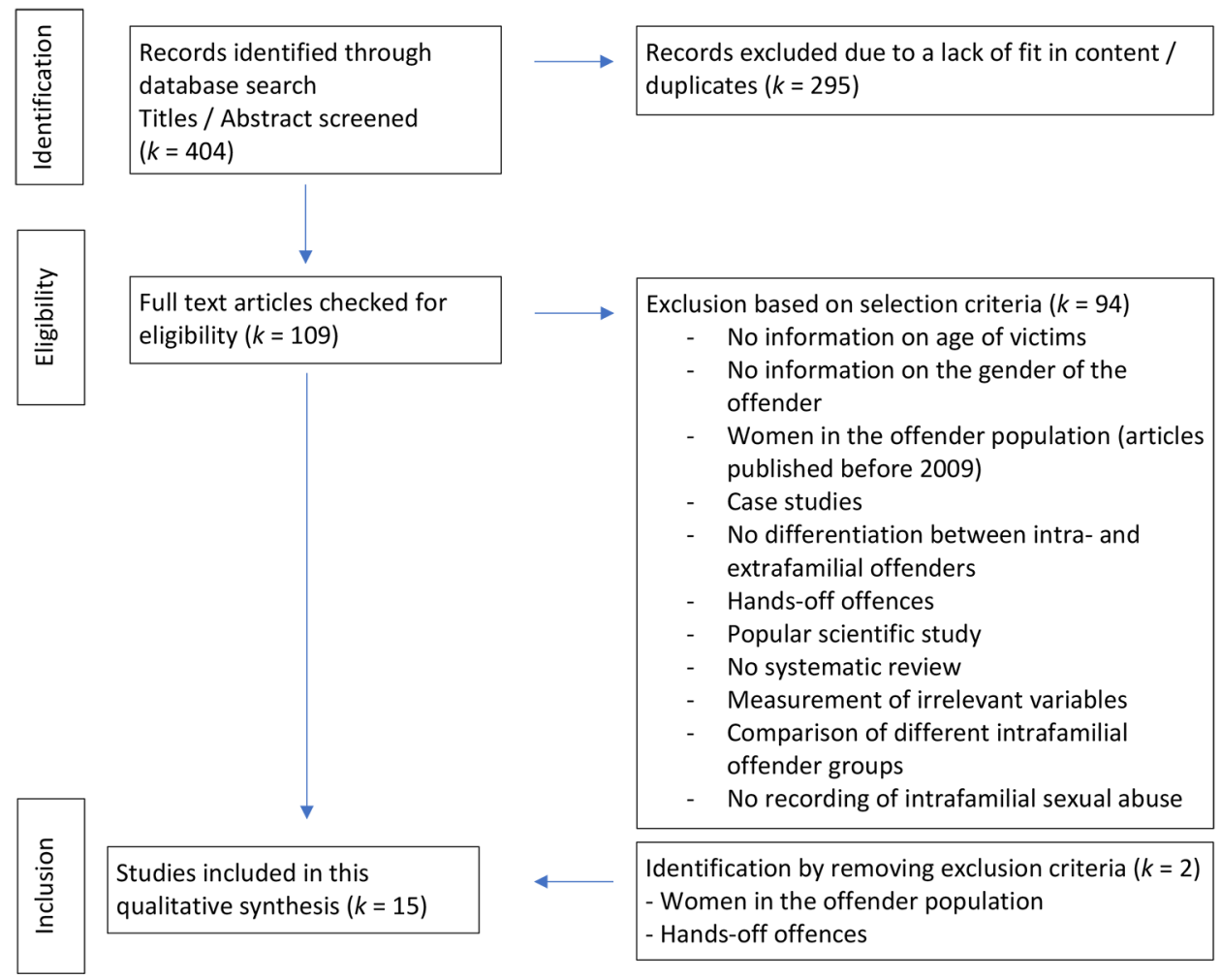

\section{Results}

\section{Characteristics of the Studies}

An overview of the included articles is presented in Table 1 (see Supplementary Materials). The studies were published between June 1991 and November 2020, with the majority $(k=9 ; 60 \%)$ published before 2000 . They were published in the United States $(k=9 ; 60 \%)$, Canada $(k=3 ; 20 \%)$, Austria $(k=1 ; 6.6 \%)$, Australia $(k=1 ; 6.6 \%)$, and Israel $(k=1 ; 6.6 \%)$. The sample sizes of intrafamilial offenders ranged from $n=12$ to $n=$ 314 , those of victims from $n=17$ to $n=137$. The gender of the victims was exclusively female in ten studies (66.7\%) and both female and male in five studies (33.3\%). Abuse was perpetrated by fathers or stepfathers or partners of the mother in six articles (40\%), by siblings (brothers or sisters) in four studies (26.7\%), and by the brothers in three studies (20\%). One study (6.6\%) examined a mixed group of male perpetrators, with fathers, 
stepfathers or foster fathers representing the largest share of perpetrators; another study (6.6\%) examined incest by the father, stepfather or foster father with the involvement of the grandfather or a brother. Only three studies (20\%) calculated the age of the victim at the beginning of abuse, which was 9 (Tener et al., 2020), 7 (Adler \& Schutz, 1995) and 8.9 years (Laviola, 1992). Not all studies reported both absolute values and percentages. In these cases, only the absolute values given in the original papers are reported.

An overview of the constructs, the instruments, and the control groups used can be found in Table 2 (see Supplementary Materials).

\section{Original Studies}

\section{Perpetrator-Victim Relationship}

Eight studies (53.3\%) examined the perpetrator's participation in child rearing as a protective factor, and relationship problems as well as degree of kinship between offenders and victims as risk factors.

The presence of a nonbiological father in the household may significantly increase the risk of intrafamilial child sexual abuse. In the study by Stroebel and colleagues (2013), the probability of incestuous abuse was 3.2 times higher when the mother's partner was not the biological father, and in Beard and colleagues (2017) the risk of intrafamilial abuse was 2.6 times higher when a nonbiological father was living in the victim's household.

McDonald and Martinez (2017) conducted an online questionnaire with 63 individuals; 30 women and 3 men were victims of sibling abuse. The majority of the victims described multiple victimizations by the abusive sibling: $79 \%$ reported sexual and physical abuse and 77\% emotional abuse. In their study on sibling sexual abuse, Tener et al. (2020) analysed narratives of abuse and described two different types of relationship between the perpetrator and the victim. In the most common type (82 out of 163 occurrences), the dichotomous relationship between perpetrator and victim is characterized by the use of violence and coercion, whereas in the less common type the sexual relationship between the siblings is seen as a part of the daily life, a "routine" (40 occurrences). In large families (the average number of children in each family was $M=6.6$ ), siblings spent a significant amount of time with each other, which led to the development of hierarchical structures between the siblings, for example when older siblings take care of their younger siblings. In this relationship type, the roles of victim and perpetrator were more difficult to distinguish than in the violent / coercive type, and sexual behaviours tended to spread among several siblings. Laviola's (1992) study examined the relationship between the sisters and their abusive brothers using semi-structured-interviews and questionnaires. The victims described the relationship as physically abusive or unloving.

Williams and Finkelhor (1995) examined paternal involvement in child upbringing with regard to the biosocial hypothesis that a high level of involvement in child rearing may be protective against incestuous abuse. The authors compared incestuous fathers 
who were absent for a longer period of time (United States Navy members) with civilian fathers who committed incest as well as with nonincestuous fathers as controls. No link was found between the period of time fathers spent apart from their daughters and later incestuous abuse, but there was a relationship between low involvement in early child rearing and later intrafamilial sexual abuse. Lack of empathy or marital dissatisfaction had no effect on this result. Surprisingly, however, being the sole provider for a daughter for at least 30 days has been shown to increase the likelihood of incestuous abuse. This suggests that sole care alone, as opposed to a high level of involvement in child care, may not be a protective factor against incest (Williams \& Finkelhor, 1995).

Lipovsky and colleagues (1993) examined the relationships between parents and siblings in families where one sibling had been abused by the father and the other had not. The victims reported significantly more problems in their relationships with their fathers than their nonabused siblings. Significantly more victims than nonabused siblings showed pathologies with regard to their attitudes towards the father. Remarkably, the fathers did not report such relationship problems, which may reflect low empathic skills in relationships among the perpetrators. Hotte and Rafman (1992) compared characteristics of dysfunctional families in which incestuous abuse had taken place with dysfunctional families without incidents of child sexual abuse. In this study, the incestuously abused girls felt significantly less loved by their fathers than nonabused girls.

\section{The Role of the Mother}

Seven (46.7\%) studies examined aspects related to the mother of the victims: the relationship between the victims and their mother, and the mother's own experiences of abuse, psychopathology, and substance abuse.

Lack of maternal care was found to be a predictive factor for the occurrence of intrafamilial child sexual abuse, whereas high levels of maternal affection were protective against incestuous abuse (Griffee et al., 2016). In the study by Smith and Saunders (1995), mothers of girls abused by the father scored significantly lower on warmth, emotional stability and extraversion in comparison with a normative sample. According to the authors, low extraversion of the mothers can be interpreted as an indication of relationship problems. In Laviola's (1992) study 16 (94\%) out of the 17 victims of sibling abuse described the relationship with their mother as emotionally neglectful or unloving. The victims of sexual abuse tended to have more problems in their relationships with their mothers than their nonabused siblings (Lipovsky et al., 1993). Similar findings are reported by Hotte and Rafman (1992): incestuously abused girls reported a significantly worse relationship with their mothers than the comparison group, and they felt significantly less loved by their mothers.

There is some evidence for the theory of transgenerational abuse. The main idea is that abusing parents were abused themselves when they were young (Ney, 1988). Smith and Saunders (1995) reported that $34.1 \%$ of the mothers of intrafamilial sexual abused 
children had at least one incident of sexual victimization in their own childhood. In Adler and Schutz (1995) 58\% ( $n=7)$ of the mothers of adolescent offenders reported sexual and $25 \%(n=3)$ physical abuse in the past.

Maternal psychopathology may play a role in intrafamilial child sexual abuse. According to Kinzl and Biebl (1991), 27\% of the 33 incestuously abused women had mothers suffering from clinical depression and $24 \%$ of the mothers showed signs of sedative abuse.

\section{The Parental Relationship}

Seven articles (53.8\%) examined marital dissatisfaction and violence between partners in families with incestuous fathers and in one case (Worling, 1995) brothers.

Beard and colleagues (2017) described lack of affection and violent conflicts between parents in incestuous families; parental disputes were the strongest predictive factor for the occurrence of intrafamilial child sexual abuse. In the study by Stroebel and colleagues (2013), the victims of father-daughter abuse experienced significantly less affection between the parents than the control group; also verbal and physical aggression were frequent among their parents. Smith and Saunders (1995) reported that almost half of the 63 parental couples with abusive fathers, stepfathers or foster fathers had experienced considerable marital difficulties. According to Williams and Finkelhor (1995), the group of incestuous fathers had significantly higher scores for marital dissatisfaction. Adolescent offenders also reported considerable problems in their parents' relationship (Adler \& Schutz, 1995; Worling, 1995). More than two thirds of the sample $(67 \% ; n=$ 8) mentioned serious marital problems of the parents, $58 \%(n=7)$ of the parents had considered separation from their partner at least once (Adler \& Schutz, 1995). Yet, Dadds and colleagues (1991) did not find differences between incestuous families and comparisons with regard to marital dissatisfaction. Smith and Saunders (1995) examined the relationship dynamics in parental couples with an abusive father. Contrary to their assumption that dyadic relationships between an incestuous father and a nonabusive mother are often characterized by a dominant man and a passive, submissive woman, they found that mothers and abusive fathers shared similar traits. In particular, higher maternal anxiety was associated with higher anxiety among fathers who perpetrated child sexual abuse.

\section{Family Relationships}

Eleven studies (73.3\%) examined risk and protective factors of intrafamilial child sexual abuse related to family relationships: negative family atmosphere and family communication, family size, psychosocial stressors and dysfunctional relationships patterns including violence.

Using a computer-assisted self-interview, Stroebel and colleagues (2013) captured relevant family characteristics of female study participants; 51 out of 2034 participants were 
identified as victims of father-daughter abuse. In the control group of nonabused participants, the parents lived together significantly more often than in the group of abused daughters. Separation of the parents without a new mother's partner living in the same household had no effect on the likelihood of being a victim of abuse: no differences were found between the abused and the nonabused groups concerning the variable parents' separation or divorce without a new mother's partner in the participants' household. But in the abusive families, often a new partner of the mother lived in the same household after parents' separation or divorce. Single parent households or having been raised in a childcare facility were observed more often in the abused than the control group. Furthermore, the nonabused daughters reported significantly more affection from their mothers and fathers, as well as a more affectionate relationship between the parents than the abused girls. In the latter group, the relationship between the girls at high school age and their mothers was often cold, and the relation between the parents was characterized by verbal aggression, lack of love and affection, and physical aggression. The abused group also reported significantly more incidents of nudity between fathers and daughters both in pre- and post-pubertal age. In order to identify the predictors of father-daughter abuse, a multiple logistic regression analysis was conducted. In descending order, the predictors were: physical violence between parents, accepted nudity between fathers and daughters, low maternal affection, and a nonbiological father living in the same household (Stroebel et al., 2013). Beard and colleagues (2017) replicated this study with 74 victims of father-daughter abuse and 355 victims of extrafamilial offenders. They confirmed the variables mentioned above as the main risk factors for father-daughter abuse: parental fighting, tolerated nudity between fathers and daughters, the presence of a male other than the biological father in the home, and low affection between the parents. According to the authors, parental fighting and the lack of affection between the parents may leave a void in the husband, which he tries to fill first emotionally and ultimately sexually in the abusive relationship with the daughter. At high school age, victims of father-daughter abuse were significantly more likely to be estranged from both parents than victims of extrafamilial child sexual abuse. Good relationships with all members of the family of origin were less frequent among intrafamilial compared to extrafamilial victims.

The study by Griffee and colleagues (2016) investigated sibling abuse with both female and male perpetrators and female and male victims. In descending order, the following factors were predictive of sibling abuse: having ever shared a bed with a sibling, having been a victim of child sexual abuse by a parent, nudity in the family, a low level of maternal affection, and having ever bathed with a sibling. The authors suggested four groups of variables: factors that lower external barriers to sexual behaviour (such as sleeping or bathing together); factors that promote nudity in the family and allow children to see their parents' genitalia; factors that eroticize young children (e.g., sexual abuse by a parent); factors that cause siblings to depend on each other for affection (for 
instance as a consequence of little maternal care). According to Tener et al. (2020), strong boundaries between the parent and the sibling subsystem are the most common trait of families where sibling sexual abuse took place. In many abusive families, the sibling subsystem is expected to function autonomously from the parental subsystem. Hence, older siblings (instead of the parents) tend to have authority as well as responsibility over their younger brothers and sisters. McDonald and Martinez (2017) investigated abuse between siblings with both male and female perpetrators and victims. Thirteen participants saw their victimization as related to dysfunctional family patterns, with eight growing up in families with absent, neglectful or abusive parents. The victims considered their parents responsible for the abuse inasmuch as they did not make sufficient efforts to protect the victims, to discipline the offender, or to adequately supervise the children.

Worling (1995) reported higher levels of family dysfunction among both intra- and extrafamilial offenders. However, intrafamilial offenders had significantly higher levels of marital problems, physical punishment, negative family atmosphere, parental rejection than extrafamilial offenders, as well as lower satisfaction with the family.

The family composition seems to play a role in intrafamilial child sexual abuse. Male teenagers who abused their siblings also had significantly more younger siblings in the household than extrafamilial juvenile offenders (Worling, 1995). Laviola (1992) found that families in which intrafamilial abuse took place had many children $(n=13$ of the families of origin of the victims had four or more children). In Kinzl and Biebl (1991), $54 \%$ of the families had at least four children. In the McDonald and Martinez (2017) study the abused children also had an average of three siblings. In the study by Tener et al. (2020), the average number of children in families with sibling sexual abuse was higher than the Israeli national average (6.6 versus 2.4). Hotte and Rafman (1992) did not report differences between families with abused daughters and controls concerning the number of children per family.

In most of the families $(n=12)$ in the study by Laviola (1992), other forms of incestuous abuse occurring among other family members in addition to sibling sexual abuse were reported. Female victims of sibling abuse rated their families as dysfunctional with respect to parenting, family relationship patterns, and coping with family stressors. Disciplinary measures often included verbal or physical abuse (e.g., hitting with objects, derogatory labelling or mocking the children in front of their siblings). The victims described the relationship with their parents as emotionally neglectful; the parents seemed to have no interest in the needs and feelings of the girls. Overall, interaction patterns prevailed that ruled out talking about feelings and family problems. Men and fathers were often described as superior in the family hierarchy, controlling and dominating women and children. Family stressors, such as illness of family members, parental depression or financial hardship, were frequent.

Kinzl and Biebl (1991) described psychosocial stressors in 33 families at onset of intrafamilial abuse. According to the female victims of incestuous abuse by fathers, 
brothers, uncles or grandfathers, $40 \%$ of the fathers showed alcohol abuse, 33\% had financial problems, and 15\% were unemployed. At abuse onset, $18 \%$ of the mothers were ill or pregnant and $12 \%$ of them were living elsewhere. Almost one quarter of the women reported severe physical aggression by their parents. Adler and Schutz (1995) found that eight (66.7\%) juvenile offenders came from families with at least one psychosocial stressor (e.g., stress, disability and / or illness) at the time of the abuse.

Dadds and colleagues (1991) examined the dynamics in incestuous families with abusive fathers from the perspective of the perpetrators, the mothers, and the abused daughters. Fathers who offended tended to perceive their family as significantly more organized than fathers in the control group. Mothers in incestuous families perceived significantly less cohesion, active-recreational orientation, and expressiveness in their families than controls. Daughters in the incestuous group tended to perceive higher levels of conflict, organization, and control, and lower levels of cohesion, expressiveness, independence, and active-recreational orientation in the family.

\section{Meta-Analytic Findings}

The meta-analytic study by Martijn et al. (2020) included 26 samples (eight published and 18 unpublished samples) with a total of 2,169 intrafamilial adolescent offenders and 2,852 extrafamilial adolescent offenders.

\section{Intrafamilial Relationships}

Compared to adolescent who perpetrated abuse on extrafamilial victims, adolescents with intrafamilial victims reported more disturbed family backgrounds; the effect sizes were moderate to large. Higher levels of family dysfunction, a higher likelihood of divorced parents, more disruptions in parenting, a higher likelihood of being placed in foster care, as well as a higher number of children in the family were reported. Furthermore, intrafamilial offenders experienced significantly more maltreatment during childhood, physical and emotional abuse, as well as neglect or exposure to domestic violence and sexual abuse by a parent or another family member.

\section{Discussion}

\section{Summary of Findings}

\section{Perpetrator-Victim Relationship}

The relationship between an adult or a juvenile intrafamilial offender and the victim has been described as conflictual, unloving, and sometimes violent. A sibling subsystem with a clear delimitation towards the parents may be linked to abuse. Active participation in the upbringing of the child, as opposed to mere presence, is considered a protective 
factor against the occurrence of incest. The presence of a man in the house who is not the biological father has been found to be a risk factor.

\section{The Role of the Mother}

Several studies found that the relationship between the nonoffending mother and the abused child is often characterized by coldness, neglect, and / or conflict. Children of mothers who had been abused may have a higher risk to become victims of intrafamilial sexual abuse. Furthermore, many mothers of incestuously abused girls reported (chronic) depression or drug abuse.

\section{The Parental Relationship}

In incestuous families, regardless of whether the offender is adolescent or adult, conflictual relationships between the parents have often been described. One study reported that parents of abused children tend to have similar personality traits, especially with regard to anxiety, but memories of an overbearing father are frequent in victims of intrafamilial abuse.

\section{Family Relationships}

The main predictors of intrafamilial abuse are verbal and physical confrontation between the parents, accepted nudity between father and daughter, low maternal affection and the presence of a nonbiological father in the household. Certain behaviors, such as sleeping or bathing together, are more common in abusive families. Incestuous families often show dysfunctional relationship patterns and lack of affection between family members. Family cohesion tends to be low, and there is a higher probability of psychological, physical, or sexual violence (other than incest). Psychological needs are often not communicated at all or only inadequately. Several studies reported a larger number of children in incestuous families than in control groups. Psychosocial stressors, for example the illness of one or more family members, financial problems, or paternal alcohol abuse are frequent among incestuous families.

\section{Implications for Practice}

Findings of this systematic review have implications for clinical practice. Because of the hidden nature of intrafamilial child sexual abuse, risk factors (a sexualized, neglectful or physically abusive familial environment) should be assessed on a regular basis in school settings as a part of routine medical assessments involving general practitioners and pediatricians (Caffaro, 2017). Interventions should be family-based and provide support for both the victims of abuse, and their parents and siblings. There is evidence for the effectiveness of family-based interventions including home-based parent support (Guterman et al., 2013), or multisystemic therapy (Hefti et al., 2020; Swenson et al., 2010). 
However, the long-term effects of interventions with victims of intrafamilial abuse have not been sufficiently investigated to date (Caffaro, 2017).

\section{Clinical Issues}

In the treatment of intrafamilial abuse, it is important to secure the physical and emotional security of the victim (Tener \& Silberstein, 2019). Physical security can be provided by separating the victim from the family (Harper, 2012). Emotional security pertains to the family's ability to acknowledge the abuse and its serious consequences, and to hold the perpetrator, not the victim, responsible for it (Charuvastra \& Cloitre, 2008). In addition to psychotherapy, other approaches including play therapy, art therapy, bibliotherapy and psychodrama may help to understand the complex emotional aspects of the abuse. The process of coping with abuse, especially inter-sibling abuse, may be hampered by the fact that the victims of abuse often do not see themselves as victims, and that professionals are not always able to tell apart perpetrators from victims (Tener \& Silberstein, 2019).

\section{Limitations}

\section{Dark Figure}

The true numbers of intrafamilial incest in the general population are unknown, and it is very likely that intrafamilial child sexual abuse is more common than the included studies suggest. Many cases may not be reported to the police (Neutze \& Osterheider, 2015), and only part of the perpetrators had been convicted (Stroebel et al., 2013; Williams \& Finkelhor, 1995). Thus, detected cases may not be representative of intrafamilial child sexual abuse.

\section{Inconsistencies Between Studies, Control Groups, and Sample Size}

The studies differ with respect to a number of core variables: age and gender of the victims, degree of kinship between the perpetrator and the victim, gender of the perpetrator (male vs male and female), relationship between the perpetrator and the victim, type and duration of abuse. Future research should distinguish between different types of perpetrator-victim relationships. In the meta-analysis by Pullman et al. (2017), differences between biological and sociolegal perpetrators emerged. Sociolegal incest offenders showed more antisocial tendencies and sexual self-regulation problems than biological incest offenders, who in turn had more psychopathological traits.

Control groups vary considerably across studies: in some studies nondeviant groups are used as controls, whereas in other studies extrafamilial child sexual abusers, sex offenders with adult victims or violent offenders are controls; some studies reported no comparison groups at all. The assignment of perpetrators to the intrafamily group varied across studies: in some studies, the possibility that intrafamilial perpetrators also have 
extrafamilial victims is not explicitly mentioned, but cannot be completely ruled out. Most samples in the original studies were small, potentially leading to an underestimation of effects. These methodological aspects may limit the generalization of the results.

\section{Heterogeneity of Measurements and Study Design}

The included studies used different methods and instruments (e.g., nonstructured expert interviews, semi-structured interviews, questionnaires). Retrospective data may be affected by the victim's ability to remember accurately and the willingness to disclose painful personal experiences. Only in some cases additional information provided by law enforcement officers or youth welfare records was available. Hence, distortions in relation with incomplete data cannot be ruled out. Moreover, context variables can compromise the accuracy and completeness of data. Intrafamilial offenders are often recruited from prisons or forensic facilities; those who have not yet been sentenced may be reluctant to disclose potentially self-incriminating information. The same applies to the victims. Some victims were identified via surveys of the general population, but others were specifically selected from psychiatric care or social welfare facilities.

Most studies used correlative designs, therefore not allowing for causal inference between conflictual family dynamics and child sexual abuse.

\section{Search Strategy and Bias}

A bias in the selection process cannot be ruled out. Unpublished studies, studies written in languages other than English or those which are not included in the bibliographical databases used in this study may have been overlooked. In this paper, the majority of the studies date back to the last century. The reason is unclear. One possible explanation is that family characteristics and dynamics may have not been in the focus of research on intrafamilial child sexual abuse in the last two decades. More likely, however, is that not all eligible studies could be detected through the selected search terms (for example, assuming that some eligible studies of the last two decades use different key words than previous studies).

\section{Outlook and Conclusion}

This review is based on the PRISMA criteria for scientific reviews. In total 15 articles were included. Several risk factors for intrafamilial child sexual abuse were identified, though they might be unspecific for this type of abuse. Screening for these risk factors on a regular basis can enable prevention of intrafamilial child sexual abuse or enhance early intervention. Future research on family characteristics and dynamics is needed which allows for the identification of more specific risk factors. 
Funding: The authors have no funding to report.

Acknowledgments: The authors have no additional (i.e., non-financial) support to report.

Competing Interests: There are no financial and personal relationships of any author with other people or organisations that could inappropriately influence the work.

\section{Supplementary Materials}

The Supplementary Materials contain the following items (for access see Index of Supplementary Materials below):

- Table 1: Characteristics of the included studies

- Table 2: Variables, measurement methods and comparison groups of the included studies

\section{Index of Supplementary Materials}

Pusch, S. A., Ross, T., \& Fontao, M. I. (2021). Supplementary materials to "The environment of intrafamilial offenders - A systematic review of dynamics in incestuous families" [Additional information]. PsychOpen GOLD. https://doi.org/10.23668/psycharchives.5320

\section{References}

Adler, N. A., \& Schutz, J. (1995). Sibling incest offenders. Child Abuse \& Neglect, 19(7), 811-819. https://doi.org/10.1016/0145-2134(95)00040-F

Bajos, N., Ancian, J., Tricou, J., \& Valendru, A. (2021). Sociologie des violences sexuelles au sein de l'Église catholique en France (1950-2020) [Sociology of sexual violence in the Catholic Church in France].

https://www.ciase.fr/medias/Ciase-Rapport-5-octobre-2021-Annexe-AN27-Rapport-InsermEHESS.pdf

Beard, K. W., Griffee, K., Newsome, J. E., Harper-Dorton, K. V., O’Keefe, S. L., Linz, T. D., Young, D. H., Swindell, S., Stroupe, W. E., Steele, K., Lawhon, M., \& Nichols, A. N. (2017). Father-daughter incest: Effects, risk-factors, and a proposal for a new parent-based approach to prevention. Sexual Addiction \& Compulsivity, 24(1-2), 79-107. https://doi.org/10.1080/10720162.2017.1306467

Beard, K. W., O’Keefe, S. L., Swindell, S., Stroebel, S. S., Griffee, K., Young, D. H., \& Linz, T. D. (2013). Brother-brother incest: Data from an anonymous computerized survey. Sexual Addiction \& Compulsivity, 20(3), 217-253.

Caffaro, J. (2017). Treating adult survivors of sibling sexual abuse: A relational strengths-based approach. Journal of Family Violence, 32(5), 543-552. https://doi.org/10.1007/s10896-016-9877-0 
Carlson, B. E., Maciol, K., \& Schneider, J. (2006). Sibling incest: Reports from forty-one survivors. Journal of Child Sexual Abuse, 15(4), 19-34. https://doi.org/10.1300/J070v15n04_02

Charuvastra, A., \& Cloitre, M. (2008). Social bonds and posttraumatic stress disorder. Annual Review of Psychology, 59, 301-328. https://doi.org/10.1146/annurev.psych.58.110405.085650

Cyr, M., Wright, J., McDuff, P., \& Perron, A. (2002). Intrafamilial sexual abuse: Brother-sister incest does not differ from father-daughter and stepfather-stepdaughter incest. Child Abuse \& Neglect, 26(9), 957-973. https://doi.org/10.1016/S0145-2134(02)00365-4

Dadds, M., Smith, M., Webber, Y., \& Robinson, A. (1991). An exploration of family and individual profiles following father-daughter incest. Child Abuse \& Neglect, 15(4), 575-586.

https://doi.org/10.1016/0145-2134(91)90041-B

Faust, J., Kenny, M. C., \& Runyon, M. K. (1997). Differences in family functioning of sexually abused vs nonabused enuretics. Journal of Family Violence, 12(4), 405-416. https://doi.org/10.1023/A:1021983525981

Finkelhor, D. (1980). Sex among siblings: A survey on prevalence, variety, and effects. Archives of Sexual Behavior, 9(3), 171-194. https://doi.org/10.1007/BF01542244

Finkelhor, D., Shattuck, A., Turner, H. A., \& Hamby, S. L. (2014). The lifetime prevalence of child sexual abuse and sexual assault assessed in late adolescence. The fournal of Adolescent Health, 55(3), 329-333. https://doi.org/10.1016/j.jadohealth.2013.12.026

Griffee, K., Swindell, S., O’Keefe, S. L., Stroebel, S. S., Beard, K. W., Kuo, S.-Y., \& Stroupe, W. (2016). Etiological risk factors for sibling incest: Data from an anonymous computer-assisted selfinterview. Sexual Abuse, 28(7), 620-659. https://doi.org/10.1177/1079063214558941

Guterman, N. B., Tabone, J. K., Bryan, G. M., Taylor, C. A., Napoleon-Hanger, C., \& Banman, A. (2013). Examining the effectiveness of home-based parent aide services to reduce risk for physical child abuse and neglect: Six-month findings from a randomized clinical trial. Child Abuse \& Neglect, 37(8), 566-577. https://doi.org/10.1016/j.chiabu.2013.03.006

Harper, B. M. (2012). Moving families to future health: Reunification experiences after sibling incest. Doctorate in Social Work (DSW) Dissertations, 26.

https://repository.upenn.edu/edissertations_sp2/26

Hefti, S., Pérez, T., Fürstenau, U., Rhiner, B., Swenson, C. C., \& Schmid, M. (2020). Multisystemic therapy for child abuse and neglect: Do parents show improvement in parental mental health problems and parental stress? Fournal of Marital and Family Therapy, 46(1), 95-109. https://doi.org/10.1111/jmft.12367

Hotte, J.-P., \& Rafman, S. (1992). The specific effects of incest on prepubertal girls from dysfunctional families. Child Abuse \& Neglect, 16(2), 273-283.

https://doi.org/10.1016/0145-2134(92)90034-O

Kinzl, J., \& Biebl, W. (1991). Sexual abuse of girls: Aspects of the genesis of mental disorders and therapeutic implications. Acta Psychiatrica Scandinavica, 83(6), 427-431. https://doi.org/10.1111/j.1600-0447.1991.tb05569.x 
Kloppen, K., Mæhle, M., Kvello, Ø., Haugland, S., \& Breivik, K. (2015). Prevalence of intrafamilial child maltreatment in the Nordic countries: A review. Child Abuse Review, 24(1), 51-66. https://doi.org/10.1002/car.2324

Langevin, R., \& Watson, R. (1991). A comparison of incestuous biological and stepfathers. Annals of Sex Research, 4(2), 141-150. https://doi.org/10.1177/107906329100400203

Latzman, N. E., Viljoen, J. L., Scalora, M. J., \& Ullman, D. (2011). Sexual offending in adolescence: A comparison of sibling offenders and nonsibling offenders across domains of risk and treatment need. Journal of Child Sexual Abuse, 20(3), 245-263.

https://doi.org/10.1080/10538712.2011.571233

Laviola, M. (1992). Effects of older brother-younger sister incest: A study of the dynamics of 17 cases. Child Abuse \& Neglect, 16(3), 409-421. https://doi.org/10.1016/0145-2134(92)90050-2

Lipovsky, J. A., Saunders, B. E., \& Hanson, R. F. (1993). Parent-child relationships of victims and siblings in incest families. Journal of Child Sexual Abuse, 1(4), 35-50. https://doi.org/10.1300/J070v01n04_03

Madonna, P. G., Van Scoyk, S., \& Jones, D. P. (1991). Family interactions within incest and nonincest families. The American Journal of Psychiatry, 148(1), 46-49. https://doi.org/10.1176/ajp.148.1.46

Martijn, F. M., Leroux, E. J., Babchishin, K. M., \& Seto, M. C. (2020). A meta-analysis comparing male adolescents who have sexually offended against intrafamilial versus extrafamilial victims. Clinical Child and Family Psychology Review, 23(4), 529-552. https://doi.org/10.1007/s10567-020-00320-6

McDonald, C., \& Martinez, K. (2017). Victims' retrospective explanations of sibling sexual violence. Journal of Child Sexual Abuse, 26(7), 874-888. https://doi.org/10.1080/10538712.2017.1354953

Moher, D., Liberati, A., Tetzlaff, J., \& Altman, D. G. (2009). Preferred reporting items for systematic reviews and meta-analyses: The PRISMA statement. Annals of Internal Medicine, 151(4), 264-269. https://doi.org/10.7326/0003-4819-151-4-200908180-00135

Neutze, J., \& Osterheider, M. (2015). Missbrauch von Kindern: Aetiologie, Dunkelfeld, Opfer Zentrale Ergebnisse des Forschungsverbundes [Abuse of children: Aetiology, dark figure, victims. Central results of the research network]. http://www.mikado-studie.de/tl_files/mikado/upload/MiKADO_Zusammenfassung.pdf

Ney, P. G. (1988). Transgenerational child abuse. Child Psychiatry and Human Development, 18(3), 151-168. https://doi.org/10.1007/BF00709728

O’Keefe, S. L., Beard, K. W., Swindell, S., Stroebel, S. S., Griffee, K., \& Young, D. H. (2014). Sisterbrother incest: Data from anonymous computer assisted self interviews. Sexual Addiction \& Compulsivity, 21(1), 1-38. https://doi.org/10.1080/10720162.2013.877410

Opgroeien (2020). Het Kind en Vlaanderen [The child in Flanders]. https://www.opgroeien.be/sites/default/files/documents/kind_in_vlaanderen_2020_0.pdf

Parker, H., \& Parker, S. (1986). Father-daughter sexual abuse: An emerging perspective. The American fournal of Orthopsychiatry, 56(4), 531-549. https://doi.org/10.1111/j.1939-0025.1986.tb03486.x 
Paveza, G. J. (1988). Risk factors in father-daughter child sexual abuse: A case-control study. Journal of Interpersonal Violence, 3(3), 290-306. https://doi.org/10.1177/088626088003003003

Pullman, L. E., Sawatsky, M. L., Babchishin, K. M., McPhail, I. V., \& Seto, M. C. (2017). Differences between biological and sociolegal incest offenders: A meta-analysis. Aggression and Violent Behavior, 34, 228-237. https://doi.org/10.1016/j.avb.2017.01.003

Rice, M. E., \& Harris, G. T. (2002). Men who molest their sexually immature daughters: Is a special explanation required? fournal of Abnormal Psychology, 111(2), 329-339. https://doi.org/10.1037/0021-843X.111.2.329

Rudd, J. M., \& Herzberger, S. D. (1999). Brother-sister incest-father-daughter incest: A comparison of characteristics and consequences. Child Abuse \& Neglect, 23(9), 915-928. https://doi.org/10.1016/S0145-2134(99)00058-7

Salazar, L. F., Camp, C. M., DiClemente, R. J., \& Wingood, G. M. (2005). Sibling incest offenders. In T. P. Gullotta \& G. R. Adams (Eds.), Handbook of adolescent behavioral problems (pp. 503-518). Springer. https://doi.org/10.1007/0-387-23846-8_23

Schwartz, B. K., Cavanaugh, D., Pimental, A., \& Prentky, R. (2006). Descriptive study of precursors to sex offending among 813 boys and girls: Antecedent life experiences. Victims \& Offenders, 1(1), 61-77. https://doi.org/10.1080/15564880500498986

Seto, M. C., Babchishin, K. M., Pullman, L. E., \& McPhail, I. V. (2015). The puzzle of intrafamilial child sexual abuse: A meta-analysis comparing intrafamilial and extrafamilial offenders with child victims. Clinical Psychology Review, 39, 42-57. https://doi.org/10.1016/j.cpr.2015.04.001

Smith, D. W., \& Saunders, B. E. (1995). Personality characteristics of father/perpetrators and nonoffending mothers in incest families: Individual and dyadic analyses. Child Abuse \& Neglect, 19(5), 607-617. https://doi.org/10.1016/0145-2134(95)00019-5

Stoltenborgh, M., Van Ijzendoorn, M. H., Euser, E. M., \& Bakermans-Kranenburg, M. J. (2011). A global perspective on child sexual abuse: Meta-analysis of prevalence around the world. Child Maltreatment, 16(2), 79-101. https://doi.org/10.1177/1077559511403920

Stroebel, S. S., Kuo, S.-Y., O’Keefe, S. L., Beard, K. W., Swindell, S., \& Kommor, M. J. (2013). Risk factors for father-daughter incest: Data from an anonymous computerized survey. Sexual Abuse, 25(6), 583-605. https://doi.org/10.1177/1079063212470706

Swenson, C. C., Schaeffer, C. M., Henggeler, S. W., Faldowski, R., \& Mayhew, A. M. (2010). Multisystemic therapy for child abuse and neglect: A randomized effectiveness trial. fournal of Family Psychology, 24(4), 497-507. https://doi.org/10.1037/a0020324

Tener, D., \& Silberstein, M. (2019). Therapeutic interventions with child survivors of sibling sexual abuse: The professionals' perspective. Child Abuse \& Neglect, 89, 192-202. https://doi.org/10.1016/j.chiabu.2019.01.010

Tener, D., Tarshish, N., \& Turgeman, S. (2020). "Victim, perpetrator, or just my brother?” Sibling sexual abuse in large families: A child advocacy center study. Fournal of Interpersonal Violence, 35(21-22), 4887-4912. https://doi.org/10.1177/0886260517718831 
Tidefors, I., Arvidsson, H., Ingevaldson, S., \& Larsson, M. (2010). Sibling incest: A literature review and a clinical study. fournal of Sexual Aggression, 16(3), 347-360. https://doi.org/10.1080/13552600903511667

Williams, L. M., \& Finkelhor, D. (1995). Paternal caregiving and incest: Test of a biosocial model. The American fournal of Orthopsychiatry, 65(1), 101-113. https://doi.org/10.1037/h0079592

Witt, A., Glaesmer, H., Jud, A., Plener, P. L., Brähler, E., Brown, R. C., \& Fegert, J. M. (2018). Trends in child maltreatment in Germany: Comparison of two representative population-based studies. Child and Adolescent Psychiatry and Mental Health, 12, Article 24. https://doi.org/10.1186/s13034-018-0232-5

Worling, J. R. (1995). Adolescent sibling-incest offenders: Differences in family and individual functioning when compared to adolescent nonsibling sex offenders. Child Abuse \& Neglect, 19(5), 633-643. https://doi.org/10.1016/0145-2134(95)00021-Y

IATSO

International Association for the
Treatment of Sexual Offenders

Sexual Offending: Theory, Research, and Prevention (SOTRAP) is the official journal of the International Association for the Treatment of Sexual Offenders (IATSO).
(P) leibniz-psychology.org

PsychOpen GOLD is a publishing service by Leibniz Institute for Psychology (ZPID), Germany. 